\title{
Short sleep duration is associated with hypertension risk among adults: a systematic review and meta-analysis
}

\author{
Qijuan Wang ${ }^{1}$, Bo $\mathrm{Xi}^{1}$, Man Liu, Yanqing Zhang and Maosun Fu
}

A number of studies have reported that sleep duration might have an important role in the development of hypertension. However, the results have been inconsistent. In this study, a meta-analysis was performed to clarify the association between sleep duration and hypertension risk. PubMed, Embase and ISI web of science databases updated on 28 October 2011 were searched for eligible publications. Pooled odds ratio (OR) or relative risk (RR) with $95 \%$ confidence intervals (CI) was calculated using a random- or fixed-effect model. Six prospective $(N=9959)$ and seventeen cross-sectional $(N=105432)$ studies were identified for the data analysis on sleep duration. The results indicated that short sleep duration was associated with an increased risk of prevalent hypertension $(\mathrm{OR}=1.20,95 \% \mathrm{Cl}: 1.09-1.32, P<0.001)$, especially among subjects younger than 65 years and females. In addition, short sleep duration was also associated with an increased risk of incident hypertension among subjects younger than 65 years $(R R=1.33,95 \% \mathrm{Cl}: 1.11-1.61, P=0.002)$. Overall, there was a significant association between long sleep duration and the risk of prevalent hypertension $(\mathrm{OR}=1.11,95 \% \mathrm{Cl}: 1.05-1.17$, $P<0.001$ ). Further subgroup analysis also suggested a significant association between long sleep duration and the risk of prevalent hypertension among subjects younger than 65 years $(\mathrm{OR}=1.12,95 \% \mathrm{Cl}: 1.06-1.19, P<0.001)$. The present meta-analysis indicated that short sleep duration was associated with an increased risk of hypertension in the overall polulation and incident hypertension among subjects younger than 65 years. In addition, long sleep duration might be associated with a risk of prevalent hypertension, especially among subjects younger than 65 years.

Hypertension Research (2012) 35, 1012-1018; doi:10.1038/hr.2012.91; published online 5 July 2012

Keywords: blood pressure; meta-analysis; sleep duration

\section{INTRODUCTION}

Hypertension, which can cause severe damage to many human organs, ${ }^{1}$ contributes greatly to the morbidity and mortality of cardiovascular diseases. ${ }^{2}$ About one-third of adults worldwide are affected by hypertension each year. ${ }^{3}$ Although the awareness, treatment and control of hypertension have been improved, the success of these measures is still unacceptably low. ${ }^{4}$

Evidence has suggested that the average sleep duration declined by approximately $18 \mathrm{~min}$ from 1972 to 2005 , especially in working-age men; ${ }^{5}$ and the percentage of short sleepers has increased significantly among full-time workers from 1975 to $2006 .^{6}$ During the past couple of decades, many studies have reported the association of short or long sleep duration with a series of negative health outcomes, including mortality, ${ }^{7-9}$ cardiovascular disease, ${ }^{10,11}$ selfrated health ${ }^{12,13}$ and chronic diseases such as type 2 diabetes, metabolic syndrome, obesity, osteoporosis. ${ }^{14-18}$ Recently, growing evidence has suggested that short or long sleep duration might be associated with hypertension risk. ${ }^{19-32}$ However, the results have been inconsistent, which could be due to the differences in the studied population, the study design and insufficient statistical power.

Most recently, Dean et al. ${ }^{33}$ has performed a systematic review to investigate the association between habitual sleep duration and hypertension. However, they did not provide a quantitative risk estimate. Therefore, it is still unclear whether short or long sleep duration is associated with hypertension risk. In this study, we performed a meta-analysis to further clarify the association between sleep duration and the risk of hypertension.

\section{MATERIALS AND METHODS}

Literature and search strategy

We searched the literature databases, including PubMed, Embase and ISI Web of Science. The search strategy to identify all possible studies involved the use of the following keywords: ('sleep') and ('blood pressure' or 'hypertension') and ('adult'). The reference lists of retrieved articles were manually searched. The relevant papers were restricted to ones published in the English language. If more than one study was published using the same case series, only the 
study with the largest sample size was included. The literature search was updated on 28 October 2011.

\section{Inclusion criteria and data extraction}

Studies were included if they met the following inclusion criteria: (1) using cross-sectional, case-control or cohort design; and (2) evaluating the association between sleep duration and hypertension in adults. The following information was extracted from each study: (1) name of the first author; (2) year of publication; (3) country of origin; (4) ethnicity of study population; (5) study design; (6) gender distribution and mean age of study population; (7) sample size; (8) sleep duration assessment; (9) hypertension assessment; (10) odds ratio (OR) or relative risk (RR) with $95 \%$ confidence interval (CI); and (11) covariate adjustment. If one study was prospective, the recruitment year and duration of follow-up were also extracted. Two authors independently assessed the articles for compliance with the inclusion criteria, and disagreement was followed by discussion until consensus was reached.

\section{Statistical analysis}

Adjusted OR or RR with 95\% CI was extracted from the selected papers and used to assess the strength of association between sleep duration and hypertension. The pooled OR (with 95\% CI) of prevalent hypertension and the pooled RR (with 95\% CI) of incident hypertension were separately calculated according to the types of sleep duration (short or long). Significance was determined by $Z$ test $(P<0.05$ was considered statistically significant). The heterogeneity among studies was evaluated by the Q-statistic test and the $I^{2}$-statistic of Higgins and Thompson. ${ }^{34}$ A random- (DerSimonian-Laird method) $)^{35}$ or fixed- (Mantel-Haenszel method) ${ }^{36}$ effects model was used to calculate the pooled OR or RR in the presence $(P \leqslant 0.10)$ or the absence $(P>0.10)$ of heterogeneity, respectively. Subgroup analysis was performed based on age, gender and ethnicity. Sensitivity analysis, after removing one study at a time, was performed to evaluate the stability of the results. Begg's funnel plot, a scatter plot of effect against a measure of study size, was generated as a visual aid to detect bias or systematic heterogeneity. ${ }^{37}$ Publication bias was assessed by Egger's test ${ }^{38}(P<0.05$ was considered statistically significant). Data analysis was performed using STATA version 11 (StataCorp LP, College Station, TX, USA).

\section{RESULTS}

\section{Characteristics of the studies}

The detailed steps of our literature search are shown in Figure 1. On the basis of the search strategy and inclusion criteria, 18 papers seemed to be eligible after reading the title or abstract. After the full texts were read, the paper by Bjorvatn et al. ${ }^{39}$ was excluded because it just provided data on the association between sleep duration and systolic hypertension or diastolic hypertension alone. One paper ${ }^{40}$ that duplicated the paper by Gangwisch et al. ${ }^{19}$ was also excluded. In addition, two comments which did not provide the related data were excluded, ${ }^{41,42}$ with the exception of the one by Lima-Costa et al., ${ }^{25}$ which reported a new study concerning the association of sleep duration and hypertension. If the results were presented according to gender or age groups in one study, or if different study designs (prospective or cross-sectional) were involved in one paper, these were considered as separate studies in the data analysis. Therefore, 14 papers involving 23 studies were included in the final metaanalysis. ${ }^{19-32}$ Of them, six were prospective studies, including 9959 participants from United Kingdom $(n=2)$, Spain $(n=1)$ and United States $(n=3)$, and 17 were cross-sectional studies, including 105432 participants from the United Kingdom $(n=2)$, Spain $(n=1)$, Netherlands $(n=1)$, Korea $(n=2)$, Brazil $(n=1)$, Germany $(n=2)$, China $(n=2)$, and the United States $(n=6)$.

In each study the referent category was identified, sleep duration being $7,{ }^{20,21,26,28} 7-8^{19,23-25,30}$ or $7-9$ h per night. ${ }^{31}$ Short sleep was defined as a duration $\leqslant 5,{ }^{19,20,24,26-28} 4-5,{ }^{21} \leqslant 6^{23,25,29}$ or $<7 \mathrm{~h}$ per

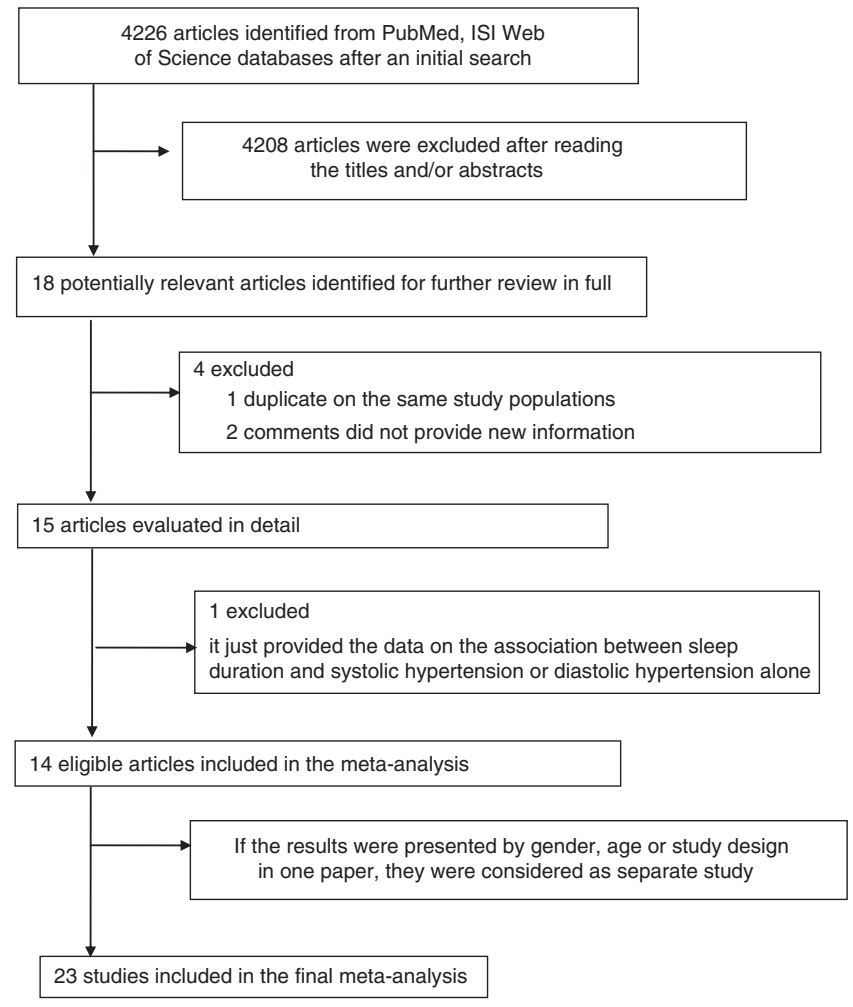

Figure 1 Selection of articles for inclusion in meta-analysis.

night. ${ }^{30-32}$ In most studies, long sleep was defined as a duration $\geqslant 9$ or $10-15 \mathrm{~h}$ per night. ${ }^{21}$ However, one study reported the OR value of short sleep duration for incident hypertension without the specific definition of sleep duration. ${ }^{22}$

Hypertension was defined as systolic blood pressure/diastolic blood pressure $(\mathrm{SBP} / \mathrm{DBP}) \geqslant 140 / 90 \mathrm{~mm} \mathrm{Hg}$, current use of antihypertensive drugs or self-report of physician's diagnosis in all of the studies except for the one by van den Berg et al. ${ }^{24}$ (which defined hypertension as $\mathrm{SBP} / \mathrm{DBP} \geqslant 160 / 100 \mathrm{~mm} \mathrm{Hg}$ or current use of antihypertensive drugs) and the study by Wang et al. ${ }^{31}$ (using SBP/DBP $\geqslant 130 / 85 \mathrm{~mm} \mathrm{Hg}$ or physician diagnosed hypertension as the definition). The characteristics of the included studies are listed in Tables 1 and 2 .

\section{Short sleep duration and hypertension}

Six prospective studies involving 9959 participants were included in the meta-analysis. The overall result showed that short sleep duration was not associated with the risk of incident hypertension $(\mathrm{RR}=1.11$, 95\% CI: $0.84-1.47, \quad P=0.470)$, with evidence of heterogeneity between studies $\left(I^{2}=55.3 \%, P=0.048\right)$ and no evidence of publication bias $(P=0.068)$ (Table 3$)$. Further subgroup analysis by age suggested a significant association between short sleep duration and the risk of incident hypertension among subjects younger than 65 years $(\mathrm{RR}=1.33,95 \% \mathrm{CI}: 1.11-1.61, P=0.002)$ but not among ones older than 65 years (Table 3). In addition, the between-study heterogeneity disappeared within each of the two subgroups.

A total of 17 cross-sectional studies involving 105432 participants were included in the meta-analysis, and the result indicated that short sleep duration was significantly associated with an increased risk of prevalent hypertension ( $\mathrm{OR}=1.20,95 \%$ CI: 1.09-1.32, $P<0.001)$, with evidence of heterogeneity between studies $\left(I^{2}=59.1 \%\right.$, $P=0.001)$ and no evidence of publication bias $(P=0.857)$ (Table 3 , Figure 2$)$. The sensitivity analysis indicated that the estimates ranged 
Table 1 Description of the prospective studies included in the meta-analysis

\begin{tabular}{|c|c|c|c|c|c|c|c|c|c|c|}
\hline Author & $\begin{array}{c}\text { Year, } \\
\text { publication }\end{array}$ & Country & $\begin{array}{c}\text { Year, } \\
\text { baseline }\end{array}$ & $\begin{array}{l}\text { Follow-up } \\
\text { (years) }\end{array}$ & Gender & $\begin{array}{l}\text { Mean age (age } \\
\text { range) (years) }\end{array}$ & $\begin{array}{l}\text { Sleep category } \\
\text { (hours) }\end{array}$ & Sample size & $\begin{array}{l}\text { Sleep duration } \\
\text { assessment }\end{array}$ & $\begin{array}{l}\text { Hypertension } \\
\text { assessment }\end{array}$ \\
\hline Gangwisch $^{19}$ & 2006 & USA & 1982-1984 & $8-10$ & $\begin{array}{l}\text { Male } \\
\text { Female }\end{array}$ & $\begin{array}{l}32-59 \\
60-86\end{array}$ & $\begin{array}{l}\text { Referent }={ }^{\prime} 7-8 ’ \\
\text { Short }=` \leqslant 5 ' \\
\text { Long }=` \geqslant 9 ’\end{array}$ & $\begin{array}{l}3610 \text { (32 -59 } \\
\text { years) } \\
1190 \text { ( } 60-86 \\
\text { years) }\end{array}$ & Questionnaire & Self-report \\
\hline Cappuccio 20 & 2007 & UK & 1997-1999 & 5 & $\begin{array}{l}\text { Male } \\
\text { Female }\end{array}$ & $\begin{array}{l}55.4 \pm 6.0 \\
56.1 \pm 6.1\end{array}$ & $\begin{array}{l}\text { Referent }={ }^{`} 7 \\
\text { Short }={ }^{\prime} \leqslant 5 \\
\text { Long }=` \geqslant 9\end{array}$ & $\begin{array}{l}2686 \text { (male) } \\
1005 \text { (female) }\end{array}$ & Questionnaire & Measurement \\
\hline $\begin{array}{l}\text { Lopez- } \\
\text { Garcia }^{21}\end{array}$ & 2009 & Spain & 2001 & 2 & $\begin{array}{l}\text { Male } \\
\text { and } \\
\text { female }\end{array}$ & $\geqslant 65$ & $\begin{array}{l}\text { Referent = '7-8' } \\
\text { Short = '4-5' } \\
\text { Long = '10-15' }\end{array}$ & 890 & Questionnaire & Self-report \\
\hline Knutson 22 & 2009 & USA & 2000-2001 & 5 & $\begin{array}{l}\text { Male } \\
\text { and } \\
\text { female }\end{array}$ & $40.1 \pm 3.6$ & Not available & 578 & $\begin{array}{l}\text { Objective } \\
\text { measurement }\end{array}$ & Measurement \\
\hline
\end{tabular}

Table 2 Description of the cross-sectional studies included in the meta-analysis

\begin{tabular}{|c|c|c|c|c|c|c|c|c|}
\hline Author & $\begin{array}{c}\text { Year, } \\
\text { publication }\end{array}$ & Country & Gender & $\begin{array}{c}\text { Mean age } \\
\text { (age range) (years) }\end{array}$ & $\begin{array}{l}\text { Sleep category } \\
\text { (hours) }\end{array}$ & Sample size & $\begin{array}{l}\text { Sleep duration } \\
\text { assessment }\end{array}$ & $\begin{array}{l}\text { Hypertension } \\
\text { assessment }\end{array}$ \\
\hline Gottlieb 23 & 2006 & USA & $\begin{array}{l}\text { Male and } \\
\text { female }\end{array}$ & $63.1 \pm 10.7$ & $\begin{array}{l}\text { Referent }={ }^{`} 7-8{ }^{\prime} \\
\text { Short }=` \leqslant 6 ' \\
\text { Long }={ }^{\prime} \geqslant 9 ’\end{array}$ & 5910 & Questionnaire & Measurement \\
\hline Cappuccio 20 & 2007 & UK & $\begin{array}{l}\text { Male } \\
\text { Female }\end{array}$ & $\begin{array}{l}55.4 \pm 6.0 \\
56.1 \pm 6.1\end{array}$ & $\begin{array}{l}\text { Referent }={ }^{`} 7 \\
\text { Short }={ }^{\prime} \leqslant 5 \\
\text { Long }={ }^{\prime} \geqslant 9 ’\end{array}$ & $\begin{array}{l}4199 \text { (male) } \\
1567 \text { (female) }\end{array}$ & Questionnaire & Measurement \\
\hline van den Berg²4 & 2007 & Netherlands & $\begin{array}{l}\text { Male and } \\
\text { female }\end{array}$ & $72.1 \pm 7.5$ & $\begin{array}{l}\text { Referent ='7-8' } \\
\text { Short }=` \leqslant 5 ' \\
\text { Long }={ }^{\prime} \geqslant 9 ’\end{array}$ & 5058 & Questionnaire & Measurement ${ }^{a}$ \\
\hline Lima-Costa 25 & 2008 & Brazil & $\begin{array}{l}\text { Male and } \\
\text { female }\end{array}$ & 68.9 & $\begin{array}{l}\text { Referent }={ }^{\prime} 7-8{ }^{\prime} \\
\text { Short }=` \leqslant 6{ }^{\prime} \\
\text { Long }={ }^{\prime} \geqslant 9 '\end{array}$ & 1423 & Questionnaire & Measurement \\
\hline Stang 26 & 2008 & German & $\begin{array}{l}\text { Male and } \\
\text { female }\end{array}$ & $<65$ & $\begin{array}{l}\text { Referent }={ }^{\prime} 7 ' \\
\text { Short }=` \leqslant 5 ' \\
\text { Long }={ }^{\prime} \geqslant 9 '\end{array}$ & $\begin{array}{l}2374 \text { (male) } \\
2423 \text { (female) }\end{array}$ & - & - \\
\hline Lopez-Garcia ${ }^{21}$ & 2009 & Spain & $\begin{array}{l}\text { Male and } \\
\text { female }\end{array}$ & $\geqslant 65$ & $\begin{array}{l}\text { Referent = '7-8' } \\
\text { Short = '4-5' } \\
\text { Long = '10-15' }\end{array}$ & 3686 & Questionnaire & Self-report \\
\hline Vgontzas $^{27}$ & 2009 & USA & $\begin{array}{l}\text { Male and } \\
\text { female }\end{array}$ & $48.7 \pm 13.5$ & $\begin{array}{l}\text { Referent }={ }^{\prime}>6{ }^{\prime} \\
\text { Short }={ }^{\prime}<5\end{array}$ & 1741 & $\begin{array}{l}\text { Objective } \\
\text { measurement }\end{array}$ & Measurement \\
\hline $\mathrm{Kim}$ and $\mathrm{Jo}^{28}$ & 2010 & Korea & $\begin{array}{l}\text { Male } \\
\text { Female }\end{array}$ & $\begin{array}{l}<65 \\
\geqslant 65\end{array}$ & $\begin{array}{l}\text { Referent }={ }^{\prime} 7 ' \\
\text { Short }={ }^{\prime} \leqslant 5 ' \\
\text { Long }={ }^{\prime} \geqslant 9 '\end{array}$ & $\begin{array}{l}4515(<65 \\
\text { years }) \\
878(\geqslant 65 \\
\text { years })\end{array}$ & Questionnaire & Measurement \\
\hline Stranges $^{29}$ & 2010 & USA & $\begin{array}{l}\text { Male and } \\
\text { female }\end{array}$ & $<60$ & $\begin{array}{l}\text { Referent }={ }^{\prime} \geqslant 6^{\prime} \\
\text { Short }={ }^{\prime}<6 '\end{array}$ & $\begin{array}{l}1317 \text { (male) } \\
1710 \text { (female) }\end{array}$ & Questionnaire & Measurement \\
\hline $\begin{array}{l}\text { Buxton and } \\
\text { Marcelli30 }\end{array}$ & 2010 & USA & $\begin{array}{l}\text { Male and } \\
\text { female }\end{array}$ & $45 \pm 17$ & $\begin{array}{l}\text { Referent ='7-8' } \\
\text { Short }=\text { ' }<7 \text { ' } \\
\text { Long }=\text { ' }>8 \text { ' }\end{array}$ & 56507 & Questionnaire & Measurement \\
\hline Wang 31 & 2011 & China & $\begin{array}{l}\text { Male and } \\
\text { female }\end{array}$ & $18-65$ & $\begin{array}{l}\text { Referent ='7-9' } \\
\text { Short }={ }^{\prime}<7 ' \\
\text { Long }={ }^{\prime} \geqslant 9 '\end{array}$ & $\begin{array}{l}1033 \text { (male) } \\
783 \text { (female) }\end{array}$ & Questionnaire & Measurement ${ }^{\mathrm{b}}$ \\
\hline Bansil $^{32}$ & 2011 & USA & $\begin{array}{l}\text { Male and } \\
\text { female }\end{array}$ & $<60$ & $\begin{array}{l}\text { Referent }={ }^{\prime} \geqslant 7 ' \\
\text { Short }={ }^{\prime}<7 '\end{array}$ & 10308 & Questionnaire & Measurement \\
\hline
\end{tabular}

aHypertension was defined as SBP/DBP $\geqslant 160 / 100 \mathrm{~mm} \mathrm{Hg}$, or current use of antihypertensive medication.

${ }^{b}$ Hypertension was defined as SBP/DBP $\geqslant 130 / 85 \mathrm{~mm} \mathrm{Hg}$, or physician-diagnosed hypertension. 
Table 3 Pooled ORs and 95\% Cls of the association between sleep duration and hypertension risk

\begin{tabular}{ccccccccc}
\hline & No of & & & & Statistical & $\mathrm{I}^{2}$ \\
Contrasts & studies & OR & $95 \%$ & $\mathrm{Cl}$ & $\mathrm{P}_{Z}$ & model & (\%) & $\mathrm{P}_{H}$ \\
\hline
\end{tabular}

Prospective studies

Short sleep

\begin{tabular}{|c|c|c|c|c|c|c|c|}
\hline All & 6 & 1.11 & $0.84-1.47$ & 0.470 & Random & 55.3 & 0.048 \\
\hline \multicolumn{8}{|c|}{ Age (years) } \\
\hline$<65$ & 4 & 1.33 & $1.11-1.61$ & 0.002 & Fixed & 29.6 & 0.23 \\
\hline$\geqslant 65$ & 2 & 0.74 & $0.47-1.14$ & 0.169 & Fixed & 0.0 & 45 \\
\hline
\end{tabular}

\begin{tabular}{|c|c|c|c|c|c|c|c|}
\hline \multicolumn{8}{|c|}{ Long sleep } \\
\hline All & 5 & 0.83 & $0.52-1.33$ & 0.606 & Random & 57.7 & 0.051 \\
\hline \multicolumn{8}{|c|}{ Age (years) } \\
\hline$<65$ & 3 & 0.86 & $0.58-1.28$ & 0.457 & Fixed & 47.7 & 0.148 \\
\hline$\geqslant 65$ & 2 & 0.87 & $0.36-2.06$ & 0.748 & Random & 81.3 & 0.021 \\
\hline
\end{tabular}

Cross-sectional studies

Short sleep

\begin{tabular}{|c|c|c|c|c|c|c|c|}
\hline All & 17 & 1.20 & $1.09-1.32$ & $<0.001$ & Random & 59.1 & 0.001 \\
\hline \multicolumn{8}{|l|}{ Age (years) } \\
\hline$<65$ & 13 & 1.26 & $1.13-1.39$ & $<0.001$ & Random & 63.1 & 0.001 \\
\hline$\geqslant 65$ & 4 & 0.99 & $0.84-1.16$ & 0.910 & Fixed & 0.0 & 0.848 \\
\hline \multicolumn{8}{|l|}{ Gender } \\
\hline Male & 4 & 1.03 & $0.91-1.18$ & 0.611 & Fixed & 0.0 & 0.400 \\
\hline Female & 4 & 1.35 & $1.18-1.55$ & 0.000 & Fixed & 7.8 & 0.354 \\
\hline \multicolumn{8}{|l|}{ Ethnicity } \\
\hline Caucasian & 10 & 1.15 & $0.99-1.34$ & 0.063 & Random & 67.1 & 0.001 \\
\hline East & 4 & 1.34 & $1.13-1.59$ & 0.001 & Fixed & 0.0 & 0.811 \\
\hline \multicolumn{8}{|l|}{ Asian } \\
\hline Mixed & 3 & 1.21 & $1.01-1.44$ & 0.034 & Random & 77.3 & 0.012 \\
\hline \multicolumn{8}{|l|}{ Long sleep } \\
\hline All & 13 & 1.11 & $1.05-1.17$ & $<0.001$ & Fixed & 33.6 & 0.114 \\
\hline \multicolumn{8}{|l|}{ Age (years) } \\
\hline$<65$ & 9 & 1.12 & $1.06-1.19$ & $<0.001$ & Fixed & 23.0 & 0.239 \\
\hline$\geqslant 65$ & 4 & 1.00 & $0.85-1.17$ & 0.978 & Fixed & 48.8 & 0.119 \\
\hline \multicolumn{8}{|l|}{ Gender } \\
\hline Male & 3 & 1.23 & $0.78-1.96$ & 0.373 & Random & 55.5 & 0.106 \\
\hline Female & 3 & 1.13 & $0.92-1.40$ & 0.243 & Fixed & 25.1 & 0.263 \\
\hline \multicolumn{8}{|l|}{ Ethnicity } \\
\hline Caucasian & 8 & 1.08 & 0.99-1.19 & 0.088 & Fixed & 24.5 & 0.233 \\
\hline East & 4 & 1.39 & $0.95-2.05$ & 0.094 & Random & 51.5 & 0.103 \\
\hline \multicolumn{8}{|l|}{ Asian } \\
\hline Mixed & 1 & 1.10 & $1.03-1.19$ & 0.555 & - & - & - \\
\hline
\end{tabular}

Abbreviations: $\mathrm{Cl}$, confidence interval; OR, odds ratio.

$P_{\mathrm{H}}, P$ value based on $Q$ test for between-study heterogeneity.

$P_{Z}, P$ value for $Z$ test.

from $1.17(1.10-1.24)$ to $1.23(1.16-1.29)$ by excluding one study at a time, which further confirmed the positive association. Subsequent subgroup analysis by age suggested a significant association between short sleep duration and prevalent hypertension risk among subjects younger than 65 years $(\mathrm{OR}=1.26,95 \% \mathrm{CI}: 1.13-1.39, P<0.001)$ but no association among subjects older than 65 years (Table 3 ). In the stratified analysis by gender, the statistically significant association was observed among the female population $(\mathrm{OR}=1.35,95 \% \mathrm{CI}$ : $1.18-1.55, \quad P=0.000)$ but not among the male population (Table 3). Meanwhile, the between-study heterogeneity disappeared within both subgroups. Moreover, subgroup analysis based on ethnicity also showed a significant association between short sleep and the risk of prevalent hypertension among the East Asian population $(\mathrm{OR}=1.34,95 \% \mathrm{CI}: 1.13-1.59, P=0.001)$ but not among Caucasians (Table 3).

\section{Long sleep duration and hypertension}

Five prospective studies involving 9381 participants were included in the meta-analysis. The overall result showed that long sleep duration was not associated with the risk of incident hypertension $(\mathrm{RR}=0.83$, 95\% CI: $0.52-1.33, \quad P=0.606)$, with evidence of heterogeneity between studies $\left(I^{2}=57.7 \%, P=0.051\right)$ and no evidence of publication bias $(P=0.249)$. Further subgroup analysis showed that there was no statistically significant association among either subjects younger than 65 years or older than 65 years (Table 3 ).

A total of 13 cross-sectional studies involving 90356 participants were included in the meta-analysis, and the result showed that there was a significant association between long sleep duration and an increased risk of prevalent hypertension $(\mathrm{OR}=1.11,95 \% \mathrm{CI}$ : $1.05-1.17, P<0.001)$, with moderate heterogeneity between studies $\left(I^{2}=33.6 \%, \quad P=0.114\right)$ and no evidence of publication bias $(P=0.555)$. The sensitivity analysis indicated that the estimates ranged from $1.09(1.03-1.16)$ to $1.12(1.06-1.19)$ by excluding one study at a time. Further subgroup analysis by age suggested a significant association between long sleep duration and the risk of prevalent hypertension among subjects younger than 65 years $(\mathrm{OR}=1.12$, 95\% CI: $1.06-1.19, P<0.001)$ but no association among ones older than 65 years. However, there was no statistically significant association among each subgroup according to gender or ethnicity (Table 3).

\section{DISCUSSION}

To our knowledge, our present study was the first meta-analysis investigating the association between sleep duration and risk of hypertension. The results from cross-sectional studies suggested statistically significant associations between short and long sleep duration and the risk of prevalent hypertension, confirming the presence of a U-shape association. The stability of sensitivity analyses and absence of publication biases further confirmed the positive associations. Moreover, subgroup analyses indicated that short sleep duration was significantly associated with prevalent hypertension among subjects younger than 65 years, females, East Asians, and long sleep duration was significantly associated with prevalent hypertension only among subjects younger than 65 years. However, for either end of the distribution of sleep duration, the meta-analyses from prospective studies did not provide consistent results. Nevertheless, for the short sleep duration-hypertension relationship, the agespecific effect of prospective studies was in agreement with the conclusion from cross-sectional studies: that is, the significant association of short sleep duration with the risk of incident hypertension was found among subjects younger than 65 years but not among those older than 65 years.

The biological mechanism underlying the association of short sleep duration with hypertension risk remains unclear. It has been suggested that short sleep duration could increase the average 24-h blood pressure and heart rate, elevate the sympathetic nervous system activity and stimulate physical and psychosocial stressors, ${ }^{19,23,43}$ and these forces in turn could lead to sustained hypertension. In addition, altered activity of the hypothalamic pituitary adrenal axis as a result of the elevated cortisol levels, renal impairment, endothelial dysfunction and proinflammatory responses could also contribute to hypertension. ${ }^{4-46}$ In addition, some evidence points to the disruption of circadian rhythmicity and autonomic balance by chronic short sleep duration being one potential contributing 


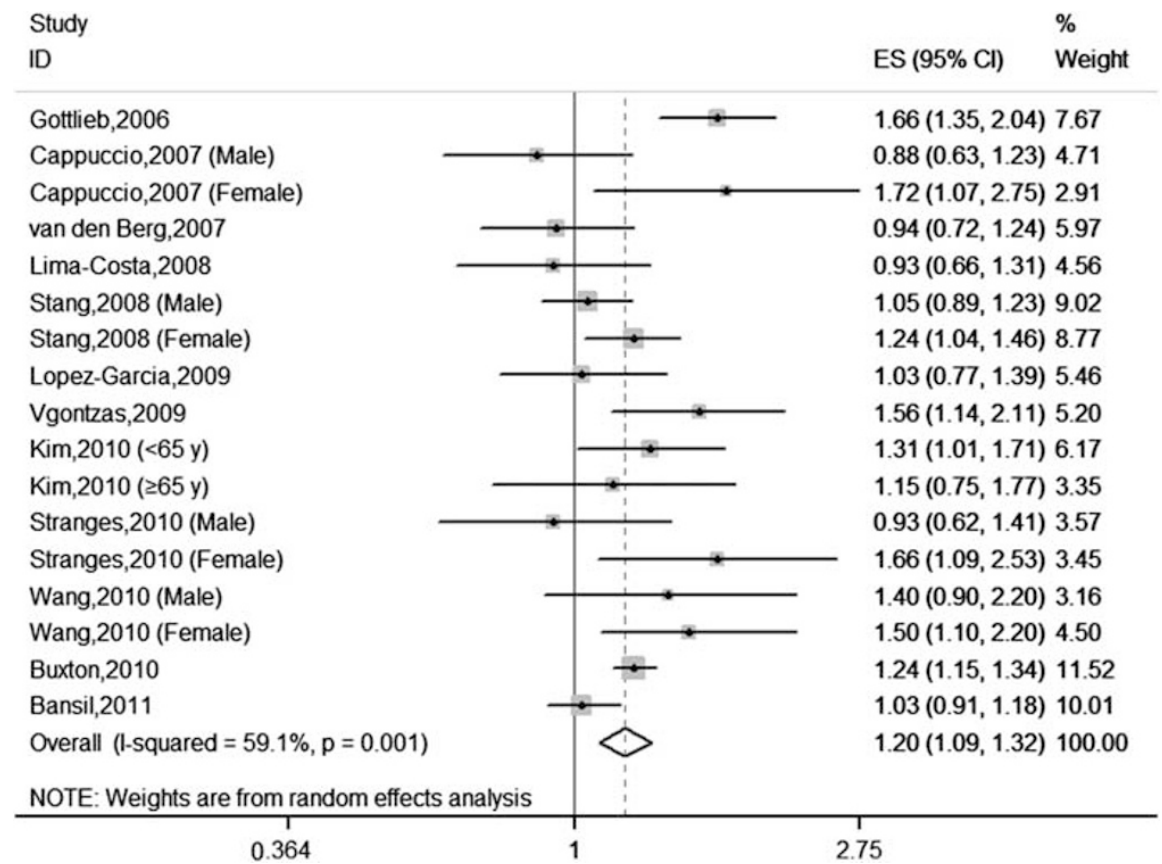

Figure 2 Meta-analysis of the association between short sleep duration and the risk of prevalent hypertension. A full color version of this figure is available at the Hypertension Research journal online.

mechanism. ${ }^{19,47}$ Finally, short sleep duration is likely to be associated with emotional changes such as irritability, impatience, pessimism and feeling tired and stressed, ${ }^{48}$ which would make it more difficult to maintain a healthy lifestyle to protect against hypertension. ${ }^{19}$

There is evidence that the full-time workers are more likely to be short sleepers compared with part-time workers and the retired. ${ }^{6}$ With regards to potential mechanisms of the age-specific effect on the association, it should be noted that younger people, who are often full-time workers, tend to experience more work-family strains, which may directly increase their blood pressure levels, as well as reduce their sleep duration or influence behaviors such as physical activity, diet and tobacco consumption to elevate their blood pressure levels. ${ }^{49}$ Another possibility is that older people, who are often retired, have a decreased demand for sleep and can also compensate for their nightly short sleep duration by daytime napping. ${ }^{19,23,24}$ People in poor physical condition, such as those with hypertension, diabetes and obesity, are less likely to survive into their later years, which could also partly explain the lack of association between short sleep duration and hypertension in older people. ${ }^{19}$ For the gender-specific association, the potential mechanisms are unknown. However, it is possible that the gender differences in psychosocial factors ${ }^{50}$ and in stress and responses to stress $^{51}$ may have a role in the association. Another explanation may be that women in menopause tend to be more vulnerable because of fluctuations in sex hormones. ${ }^{20}$

Moreover, it should be noted that short sleep duration may lead to increased mortality, as a result of negative health outcomes such as hypertension, cardiovascular disease, diabetes, metabolic syndrome and obesity. This is one of the possible pathways to explain the relationship between short sleep duration and mortality. However, the specific mechanism remains unknown and deserves further investigation. ${ }^{52}$ Thus, more in-depth research is required to clarify the underlying mechanisms of the short sleep duration-hypertensionmortality relationship.

Regarding the association between long sleep duration and hypertension risk, this was consistent with other relationships between long sleep duration and cardiovascular disease and mortality. ${ }^{8-11}$ However, there has hitherto been little speculation on the potential mechanisms underlying the associations of long sleep duration with morbidity and mortality. Rather, one vigorous argument has focused on sleep apnea, which could confound the associations because individuals with this disorder spend more time or an excessive amount of time asleep to compensate for the fragmented nature of their sleep. ${ }^{53}$ However, there is not sufficient evidence that people with sleep apnea sleep more than the average. ${ }^{54}$ In addition, the associations may be explained by some other residual confounding factors associated with long sleep duration such as depressive symptoms, low socio-economic status, unemployment status, being single and low education levels. ${ }^{55,56}$ And therefore long sleep duration might be a marker, rather than a causative risk factor, of morbidity and mortality. ${ }^{55}$ However, further prospective studies are required to confirm the positive association of long sleep duration with hypertension.

Several limitations of our analysis should be noted. First, the information on sleep duration was self-reported by questionnaire for most studies, with the exception of two studies (by Knutson et al. ${ }^{22}$ and Vgontzas et al., ${ }^{27}$ where the data were obtained by objective measurement with actigraphy). Nevertheless, self-reported sleep duration assessment has been validated against quantitative sleep assessments. ${ }^{22,55}$ Second, there were also a few small differences in the measurement of blood pressure or the definition of hypertension between the studies; however, in most of the included studies, hypertension was defined as SBP/DBP $\geqslant 140 / 90 \mathrm{~mm} \mathrm{Hg}$. Third, as is known, cross-sectional studies do not allow for establishing the causality of an observed association, although a positive association was found based on these studies. In addition, the sample size of the included prospective studies in our meta-analysis was so small that the result was not consistent with that of the cross-sectional studies. However, the present meta-analysis does have some strengths. For instance, the pooled results were based on adjusted estimates from multivariate regression models, including a number of confounding 
factors, although the covariates that were controlled for were somewhat different for each study.

In conclusion, our meta-analysis indicated that short sleep duration was associated with an increased risk of prevalent hypertension in the overall population, especially among subjects younger than 65 years and females, and short sleep duration was associated with an increased risk of incident hypertension only among subjects younger than 65 years. In addition, a long sleep duration might be associated with the risk of prevalent hypertension among subjects younger than 65 years. Large-scale prospective studies are needed to further investigate the causal association between sleep duration and hypertension.

\section{CONFLICT OF INTEREST}

The authors declare no conflict of interest.

\section{ACKNOWLEDGEMENTS}

This study was supported by the National 'Twelfth Five-Year' Plan for Science \& Technology Support Program (2012BAI03B03), the Independent Innovation Foundation of Shandong University (2010GN046), and the Foundation for Outstanding Young Scientist in Shandong Province (BS2011YY026).

1 Torpy JM, Lynm C, Glass RM. JAMA patient page. Hypertension. JAMA 2010; 303 : 2098

2 Lewington S, Clarke R, Qizilbash N, Peto R, Collins R. Prospective Studies Collaboration. Age-specific relevance of usual blood pressure to vascular mortality: a metaanalysis of individual data for one million adults in 61 prospective studies. Lancet 2002; 360: 1903-1913.

3 Lawes CM, Vander Hoorn S, Rodgers A. International Society of Hypertension. Global burden of blood-pressure-related disease, 2001. Lancet 2008; 371: 1513-1518.

4 Egan BM, Zhao Y, Axon RN. US trends in prevalence, awareness, treatment, and control of hypertension, 1988-2008. JAMA 2010; 303: 2043-2050.

5 Kronholm E, Partonen T, Laatikainen T, Peltonen M, Härmä M, Hublin C, Kaprio J, Aro AR, Partinen M, Fogelholm M, Valve R, Vahtera J, Oksanen T, Kivimäki M, Koskenvuo $\mathrm{M}$, Sutela $\mathrm{H}$. Trends in self-reported sleep duration and insomnia-related symptoms in Finland from 1972 to 2005: a comparative review and re-analysis of Finnish population samples. J Sleep Res 2008; 17: 54-62.

6 Knutson KL, Van Cauter E, Rathouz PJ, DeLeire T, Lauderdale DS. Trends in the prevalence of short sleepers in the USA: 1975-2006. Sleep 2010; 33: 37-45.

7 Hammond EC. Some preliminary findings on physical complaints from a prospective study of 1,064,004 men and women. Am J Public Health Nations Health 1964; 54: 11-23.

8 Cappuccio FP, D'Elia L, Strazzullo P, Miller MA. Sleep duration and all-cause mortality: a systematic review and meta-analysis of prospective studies. Sleep 2010; 33: 585-592.

9 Gallicchio L, Kalesan B. Sleep duration and mortality: a systematic review and metaanalysis. J Sleep Res 2009; 18: 148-158.

10 Cappuccio FP, Cooper D, D’Elia L, Strazzullo P, Miller MA. Sleep duration predicts cardiovascular outcomes: a systematic review and meta-analysis of prospective studies. Eur Heart J 2011; 32: 1484-1492.

11 Mosca M, Aggarwal B. Sleep duration, snoring habits, and cardiovascular disease risk factors in an ethnically diverse population. J Cardiovasc Nurs 2012; 27: 263-269.

12 Magee CA, Caputi $P$, Iverson DC. Relationships between self-rated health, quality of life and sleep duration in middle aged and elderly Australians. Sleep Med 2011; 12: 346-350.

13 Shankar A. Charumathi S, Kalidindi S. Sleep duration and self-rated health: the national health interview survey 2008. Sleep 2011; 34: 1173-1177.

14 Cappuccio FP, D'Elia L, Strazzullo P, Miller MA. Quantity and quality of sleep and incidence of type 2 diabetes: a systematic review and meta-analysis. Diabetes Care 2010: 33: 414-420.

15 Choi JK, Kim MY, Kim JK, Park JK, Oh SS, Koh SB, Eom A. Association between Short Sleep Duration and High Incidence of Metabolic Syndrome in Midlife Women. Tohoku J Exp Med 2011; 225: 187-193.

16 Cappuccio FP, Taggart FM, Kandala NB, Currie A, Peile E, Stranges S, Miller MA. Metaanalysis of short sleep duration and obesity in children and adults. Sleep 2008; 31: 619-626.

17 Chen X, Beydoun MA, Wang Y. Is sleep duration associated with childhood obesity? A systematic review and meta-analysis. Obesity 2008; 16: 265-274.

18 Kobayashi D, Takahashi O, Deshpande GA, Shimbo T, Fukui T. Association between osteoporosis and sleep duration in healthy middle-aged and elderly adults: a largescale, cross-sectional study in Japan. Sleep Breath 2012; 16: 579-583.

19 Gangwisch JE, Heymsfield SB, Boden-Albala B, Buijs RM, Kreier F, Pickering TG, Rundle AG, Zammit GK, Malaspina D. Short sleep duration as a risk factor for hypertension: analyses of the first National Health and Nutrition Examination Survey. Hypertension 2006; 47: 833-839.
20 Cappuccio FP, Stranges S, Kandala NB, Miller MA, Taggart FM, Kumari M, Ferrie JE, Shipley MJ, Brunner EJ, Marmot MG. Gender-specific associations of short sleep duration with prevalent and incident hypertension: the Whitehall II Study. Hypertension 2007; 50: 693-700.

21 Lopez-Garcia E, Faubel R, Guallar-Castillon P, Leon-Muñoz L, Banegas JR, RodriguezArtalejo F. Self-reported sleep duration and hypertension in older Spanish adults. J Am Geriatr Soc 2009; 57: 663-668.

22 Knutson KL, Van Cauter E, Rathouz PJ, Yan LL, Hulley SB, Liu K, Lauderdale DS. Association between sleep and blood pressure in midlife: the CARDIA sleep study. Arch Intern Med 2009; 169: 1055-1061.

23 Gottlieb DJ, Redline S, Nieto FJ, Baldwin CM, Newman AB, Resnick HE. Punjabi NM. Association of usual sleep duration with hypertension: the Sleep Heart Health Study. Sleep 2006; 29: 1009-1014.

24 van den Berg JF, Tulen JH, Neven AK, Hofman A, Miedema HM, Witteman JC, Tiemeier $\mathrm{H}$. Sleep duration and hypertension are not associated in the elderly. Hypertension 2007; 50: 585-589.

25 Lima-Costa MF, Peixoto SV, Rocha FL. Usual sleep duration is not associated with hypertension in Brazilian elderly: The Bambui Health Aging Study (BHAS). Sleep Med 2008; 9: 806-807.

26 Stang A, Moebus S, Möhlenkamp S, Erbel R, Jöckel KHHeinz Nixdorf Recall Study Investigative Group. Gender-specific associations of short sleep duration with prevalent hypertension. Hypertension 2008; 51: e15-e16. author reply e17.

27 Vgontzas AN, Liao D, Bixler EO, Chrousos GP, Vela-Bueno A. Insomnia with objective short sleep duration is associated with a high risk for hypertension. Sleep 2009; 32 : 491-497.

$28 \mathrm{Kim} \mathrm{J}$, Jo I. Age-dependent association between sleep duration and hypertension in the adult Korean population. Am J Hypertens 2010; 23: 1286-1291.

29 Stranges S, Dorn JM, Cappuccio FP, Donahue RP, Rafalson LB, Hovey KM, Freudenheim JL, Kandala NB, Miller MA, Trevisan M. A population-based study of reduced sleep duration and hypertension: the strongest association may be in premenopausal women. J Hypertens 2010; 28: 896-902.

30 Buxton OM, Marcelli E. Short and long sleep are positively associated with obesity, diabetes, hypertension, and cardiovascular disease among adults in the United States. Soc Sci Med 2010; 71: 1027-1036.

31 Wang H, Zee P, Reid K, Chervin RD, Patwari PP, Wang B, Li Z, Tang G, Liu X, Yang J, Xu $X$, Wang X. Gender-specific association of sleep duration with blood pressure in rural Chinese adults. Sleep Med 2011; 12: 693-699.

32 Bansil P, Kuklina EV, Merritt RK, Yoon PW. Associations between sleep disorders, sleep duration, quality of sleep, and hypertension: results from the national health and nutrition examination survey, 2005 to 2008. J Clin Hypertens Greenwich 2011; 13: 739-743.

33 Dean E, Bloom A, Cirillo M, Hong Q, Jawl B, Jukes J, Nijjar M, Sadovich S, Bruno SS. Association between habitual sleep duration and blood pressure and clinical implications: A systematic review. Blood Press 2012; 21: 45-57.

34 Higgins JP, Thompson SG, Deeks JJ, Altman DG. Measuring inconsis-tency in metaanalyses. BMJ 2003; 327: 557-560.

35 DerSimonian R, Laird N. Meta-analysis in clinical trials. Control Clin Trials 1986; 7: 177-188.

36 Mantel N, Haenszel W. Statistical aspects of the analysis of data from retrospective studies of disease. J Natl Cancer Inst 1959; 22: 719-748.

37 Begg CB, Mazumdar M. Operating characteristics of a rank correlation test for publication bias. Biometrics 1994; 50: 1088-1101.

38 Egger M, Davey Smith G, Schneider M, Minder C. Bias in meta-analysis detected by a simple, graphical test. BMJ 1997; 315: 629-634.

39 Bjorvatn B, Sagen IM, Øyane N, Waage S, Fetveit A, Pallesen S, Ursin R. The association between sleep duration, body mass index and metabolic measures in the Hordaland Health Study. J Sleep Res 2007; 16: 66-76.

40 Gangwisch JE, Malaspina D, Posner K, Babiss LA, Heymsfield SB, Turner JB Zammit GK, Pickering TG. Insomnia and sleep duration as mediators of the relationship between depression and hypertension incidence. Am J Hypertens 2010; 23: 62-69.

41 Lombardi C, Hedner J, Parati G. Sex and age differences in the relationship between sleep duration and hypertension. J Hypertens 2010; 28: 883-886.

42 Thorpy M. Association of sleep duration with hypertension. Curr Neurol Neurosci Rep 2007; 7: 159-160.

43 Lusardi P, Zoppi A, Preti P, Pesce RM, Piazza E, Fogari R. Effects of insufficient sleep on blood pressure in hypertensive patients: a 24-h study. Am J Hypertens 1999; 12 : 63-68.

44 Wolk R, Somers VK. Sleep and the metabolic syndrome. Exp Physiol 2007; 92 : 67-78.

45 Miller MA, Cappuccio FP. Inflammation, sleep, obesity and cardiovascular disease. Curr Vasc Pharmacol 2007; 5: 95-102.

46 Scheer FA, Hilton MF, Mantzoros CS, Shea SA. Adverse metabolic and cardiovascular consequences of circadian misalignment. Proc Natl Acad Sci USA 2009; 106: 4453-4458.

47 Kreier F, Yilmaz A, Kalsbeek A, Romijn JA, Sauerwein HP, Fliers E, Buijs RM. Hypothesis: shifting the equilibrium from activity to food leads to autonomic unbalance and the metabolic syndrome. Diabetes 2003; 52: 2652-2656.

48 National Sleep Foundation Sleep in America Poll. National Sleep Foundation, Washington, DC, 2002, (http://www.sleepfoundation.org/).

49 Berkman LF, Buxton O, Ertel K, Okechukwu C. Managers' practices related to work family balance predict employee cardiovascular risk and sleep duration in extended care settings. J Occup Health Psychol 2010; 15: 316-329. 
50 Wu J, Liu Y, Rao K, Sun Q, Qian J, Li Z. Education-related gender differences in health in rural China. Am J Public Health 2004; 94: 1713-1716.

51 Rediehs M, Reis J, Creason N. Sleep in old age: focus on gender differences. Sleep 1990; 13: 410-424.

52 Grandner MA, Hale L, Moore M, Patel NP. Mortality associated with short sleep duration: the evidence, the possible mechanisms, and the future. Sleep Med Rev 2010; 14: 191-203.
53 Grandner MA, Drummond SP. Who are the long sleepers? Towards an understanding of the mortality relationship. Sleep Med Rev 2007; 11: 341-360.

54 Jean-Louis G, Kripke DF, Ancoli-Israel S. Sleep and quality of well-being. Sleep 2000; 23: $1115-1121$.

55 Knutson KL, Turek FW. The U-shaped association between sleep and health: the 2 peaks do not mean the same thing. Sleep 2006; 29: 878-879.

56 Hale L. Who has time to sleep? J Public Health 2005; 27: 205-211. 